\title{
The influence of the net rainfall mixed Curve Number - Green Ampt procedure in flood hazard mapping: a case study in Central Italy
}

\author{
Andrea Petroselli, ${ }^{1}$ Ettore Arcangeletti, ${ }^{1}$ Elena Allegrini, ${ }^{1}$ Nunzio Romano, ${ }^{2}$ \\ Salvatore Grimaldi ${ }^{3}$ \\ ${ }^{1}$ Dipartimento di scienze e tecnologie per l'agricoltura, le foreste, la natura e l'energia (DAFNE), \\ University of Tuscia, Viterbo, Italy; ${ }^{2}$ Dipartimento di Agraria, Sezione di Ingegneria Agraria,
}

\begin{abstract}
A net rainfall estimation procedure, referred to as Curve-Number For Green-Ampt (CN4GA), combining the Soil Conservation Service Curve Number (SCS-CN) method and the Green and Ampt (GA) infiltration equation was recently developed, aiming to distribute at subdaily time resolution the information provided by the SCS-CN method. The initial abstraction and the total volume of rainfall provided by the SCS-CN method are used to identify the ponding time and to quantify the hydraulic conductivity parameter of the GA equation, whereas the GA infiltration model distributes the total volume of the rainfall excess provided by the SCS-CN method. In this study we evaluate the proposed procedure with reference to a real case comparing the flood mapping obtained applying the event-based approach for two different net rainfall scenarios: the proposed CN4GA and the common SCS-CN. Results underline that the net rainfall estimation step can affect the final flood mapping result.
\end{abstract}

\section{Introduction}

Since floods can alter even seriously the environment and compromise human activities and economic development, flood hazard mapping is considered as the optimal non-structural tool for sustainable urban and land planning. It plays a fundamental role in flood prevention and protection. According to the European Directive 2007/60, the assessment and management of flood risks should lead to reduce negative consequences on people and environment. As a result, effective flood prevention and mitigation are strongly needed to successfully overcome impacts of flood events [European Directive, 2007/60].

A preliminary floodplain characterization at the basin scale can be

Correspondence: Andrea Petroselli, DAFNE, Università degli Studi della Tuscia, via San Camillo de Lellis snc, 01100, Viterbo.

Tel. +39.0761.357348. E-mail:petro@unitus.it

Key words: CN4GA, flood mapping, rainfall-runoff modelling, SCS-CN method, WFIUH.

(O) Copyright A. Petroselli et al., 2013

Licensee PAGEPress, Italy

Journal of Agricultural Engineering 2013; XLIV(s2):e11

doi:10.4081/jae.2013.s2.e11

This article is distributed under the terms of the Creative Commons Attribution Noncommercial License (by-nc 3.0) which permits any noncommercial use, distribution, and reproduction in any medium, provided the orig- carried out applying simplified hydrogeomorphological methods, which mainly refer only to terrain analysis and Digital Elevation Models (DEMs) [Dodov and Foufoula-Georgiou, 2006; Nardi et al., 2006]. However, in order to gain inundation maps useful for urban and land planning, advanced hydrologic and hydraulic modeling are required. While the former provides flood peak discharges or flow hydrograph with a given return period, the latter employs a monodimensional (1D) or bidimensional (2D) hydraulic propagation models in order to accurately evaluate the spatial flow distribution. In the past years, the complex 2D models suffered from the limited amount of input data and computational burdens. Nevertheless, these limitations have been recently overcome leading to advanced approaches for accurate spatial and temporal flooding process simulations [Grimaldi et al., 2013a; Horritt et al., 2007]. As a consequence, nowadays, detailed urban development projects should include 2D modeling as a mandatory solution.

In general, the hydrological-hydraulic procedure for flood mapping includes several steps as follows [Petroselli, 2012; Sampson et al., 2012]: (1) terrain analysis for morphometric attributes; (2) design hyetograph estimation (3) net rainfall evaluation (4) rainfall-runoff modeling (5) design hydrograph quantification, and (6) hydraulic propagation model.

The present paper explores the third stage of the above sequence by providing an evaluation of a recently proposed procedure [Grimaldi $e t$ al., 2013b, 2013c], known as Curve-Number For Green-Ampt (CN4GA) that combines the Soil Conservation Service - Curve Number (SCS$\mathrm{CN}$ ) method and the Green-Ampt (GA) infiltration equation. A real case study in a small watershed -for which rainfall and flood inundated areas are available- is further investigated in the present work. Starting from gross rainfall observations, two net rainfall scenarios namely CN4GA and SCS-CN respectively- are estimated and routed by the use of 2D modeling in the selected case study. The comparison of the two flooded areas with the observed one allows to evaluate if the CN4GA procedure provides reliable results.

\section{Material and methods}

The SCS-CN method [Soil Conservation Service, 1972] is a lumped approach describing the runoff or precipitation excess $P_{e}(\mathrm{~mm})$ as a function of the accumulated gross precipitation depth $P$ (mm) according to:

$$
P_{e}=\frac{\left(P-I_{a}\right)^{2}}{P-I_{a}+S} \quad, \quad I_{a}=0.2 \cdot S \quad, S=254 \cdot\left(\frac{100}{C N}-1\right)
$$

where $I_{a}$ is the initial abstraction (mm), $S$ is the maximum potential retention $(\mathrm{mm})$, and $\mathrm{CN}$ is the Curve Number, ranging from 0 (null 
runoff) to 100 (runoff equals the gross rainfall).

The Green-Ampt (GA) method [Green and Ampt GA, 1911; Mein and Larson, 1973] is an infiltration equation exploiting Darcy's law and is based on the following expression:

$$
\left.I(t)=K_{s} t+\Delta h \cdot \Delta \theta \cdot \ln \mid 1+\frac{I(t)}{\Delta h \cdot \Delta \theta}\right\rceil
$$

where $I(t)$ is the cumulative infiltration rate $(\mathrm{mm}), K_{s}$ the saturated hydraulic conductivity $(\mathrm{mm} / \mathrm{h}), t$ is the time $(\mathrm{h}), \Delta h$ the driving matric pressure-head (mm), and $\Delta \theta(-)$ is the change in soil moisture content between the saturation condition and the initial condition (i.e. $\Delta \theta=$ $\left.\theta_{\text {sat }}-\theta_{\text {init }}\right)$. In Eq. 2 four parameters need to be quantified in order to estimate the cumulative infiltration function: $\theta_{s a t}, \theta_{\text {init }}, \Delta h$ and $K_{s}$.

Since it is inappropriate to apply the SCS-CN at sub-daily time resolution, recently, an empirical and iterative procedure [Grimaldi et al., 2013b, 2013c] (CN4GA, Curve Number for Green-Ampt) combining GA and the SCS-CN methods has been introduced. In the mixed procedure the cumulative $P_{e}$ and $I_{a}$ values are derived using the SCS-CN method and then used to estimate the ponding time and the GA hydraulic conductivity $K_{s}$, since this latter is the most difficult parameter to quantify. The others GA parameters, as shown in Grimaldi et al., 2013c, are insensitive in the CN4GA procedure and then literature values are taken into account, considering simple soil properties and assuming the permanent wilting condition as the initial dry state for $\theta_{\text {init. }}$. In doing so, two different net rainfall scenarios can be obtained: SCS-CN and CN4GA, both having the same cumulative rainfall excess value and ponding time.

The selected case study is the Fiora watershed located in Central Italy, with basin area equal to $821 \mathrm{~km}^{2}$ and with elevations ranging from 75 to $1660 \mathrm{~m}$ a.s.l.; the average basin slope is $9.8 \%$ while the land cover was derived from CORINE project [CORINE Project, 2000], and an average value of 72.45 was assigned to $\mathrm{CN}$ according to [USDA-NRCS, 2010]; for the CN4GA application, average values of the hydraulic parameters pertaining to sandy clay loam soil were used.

Four rain gauges (namely Montalto, Pitigliano, Sorano, Vulci) are available with rainfall observations at 1 hour time resolution: the rainfall event of November 11-13, 2011, has been selected and, moreover, the Thiessen polygon and the areal reduction factor methods have been employed in order to determine the average gross rainfall hyetograph. SCS-CN and CN4GA methods have been applied as previously described and the two net rainfall scenarios have been convolved with the basin IUH in order to obtain the resulting hydrographs. As IUH, the parsimonious WFIUH-1par was applied as described in [Grimaldi et al., 2010, 2012]. The concentration time $T_{c}=18$ hours and has been obtained using the NRCS empirical relation [Natural Resources Conservation Service (NRCS), 2008].

The two corresponding hydrographs have been routed implementing the 2D hydraulic model FLO-2D [FLO-2D, 2012]; topography and roughness conditions of the 2D hydraulic modeling project were derived by integrating the available digital data with field campaign. The selected hydraulic modeling domain, shown in Figure 2, is located in the proximity of the basin outlet within a large floodplain which has been flooded during the selected rainfall event: the observed flood area extension was digitized starting from orthophoto maps provided by Regione Toscana and Autorità di Bacino Interregionale del Fiume Fiora. In doing so, it is possible to compare the observed flood area with the two simulated ones.

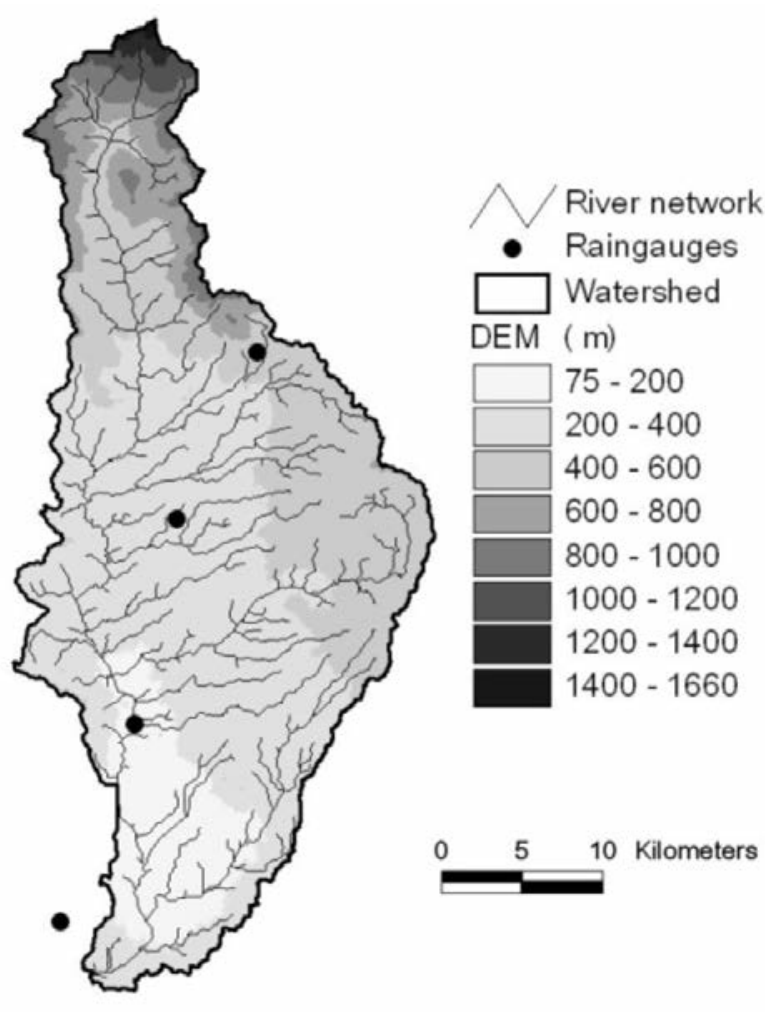

Figure 1. Case study DEM, rain gauges and drainage network.

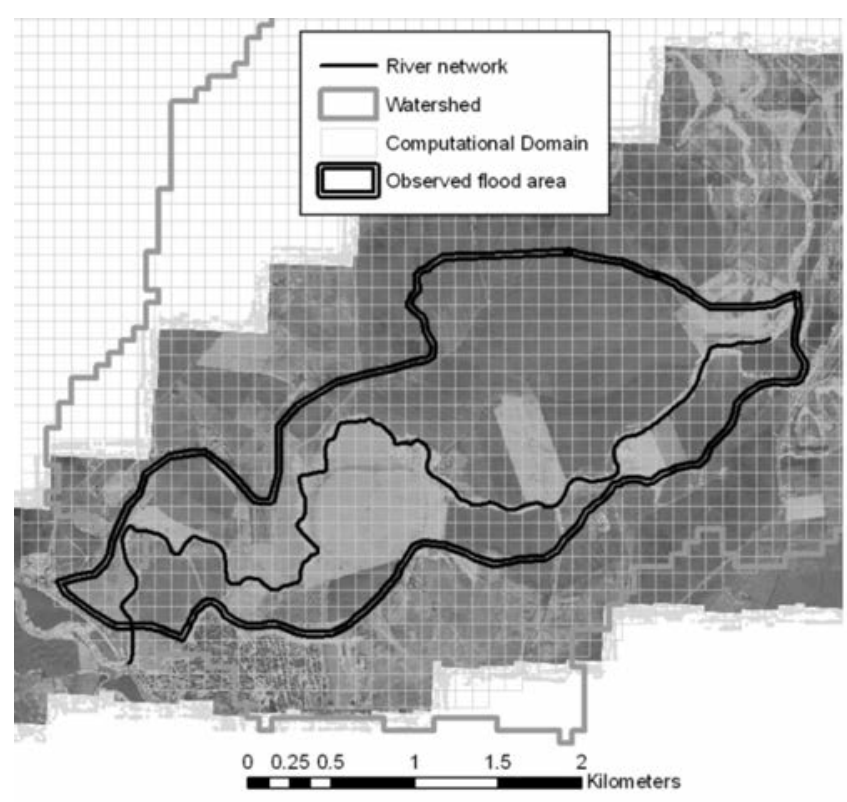

Figure 2. Case study 2D hydraulic modeling domain. Cell size resolution is $100 \mathrm{~m}$. 


\section{Results and discussion}

In Figure 3 the results of rainfall runoff modeling are reported; in the upper $\mathrm{x}$ axis the average gross hyetograph is shown together with the two estimated net hyetographs, while the two hydrographs are reported in the lower $x$ axis. With specific regard to the considered rainfall event, the observed hydrograph is not available. The gross rainfall amount is $213 \mathrm{~mm}$, while the net rainfall amount is $130 \mathrm{~mm}$ for both SCS-CN and CN4GA. Confirming previous literature results [Grimaldi et al., 2013b, 2013c] , CN4GA is more able, as respect to SCS-CN, to follow the shape of gross hyetograph, providing in this circumstance a peak discharge of $1844 \mathrm{~m}^{3} / \mathrm{s}$, while SCS-CN method provides a peak discharge of $1541 \mathrm{~m}^{3} / \mathrm{s}$. It is noteworthy that the Basin Authority "Autorità di Bacino Interregionale del Fiume Fiora" has estimated a peak discharge of $1911 \mathrm{~m}^{3} / \mathrm{s}$ for the considered event, with a return period of 361 years.

In Figure 4 the results of 2D hydraulic modeling are shown. With respect to the observed and digitized flooded area, the CN4GA flood area is similar to the corresponding one obtained with the SCS-CN

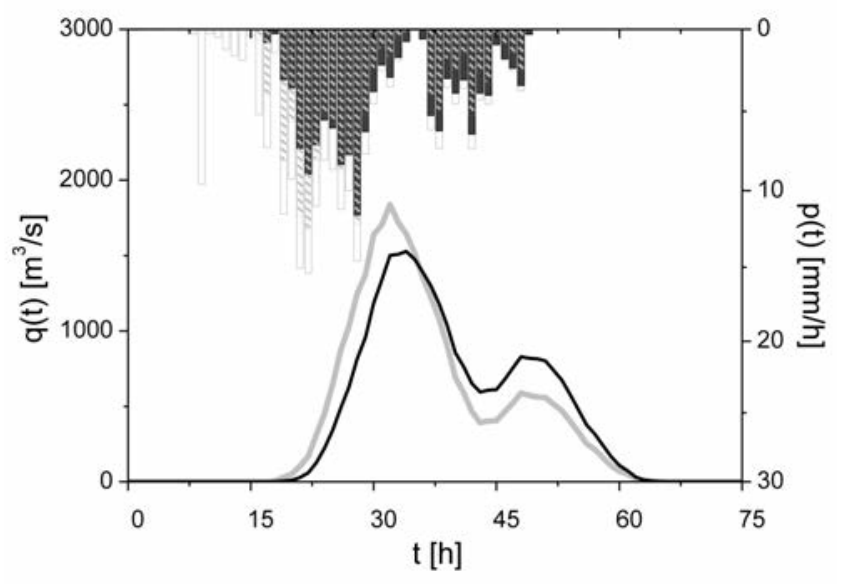

Figure 3. Results of rainfall runoff modeling. Upper $\mathrm{x}$ axis: gross rainfall (light gray), SCS-CN net rainfall (thick black), CN4GA net rainfall (thick gray). Lower $x$ axis: SCS-CN net discharge (thick black), CN4GA net discharge (thick gray).

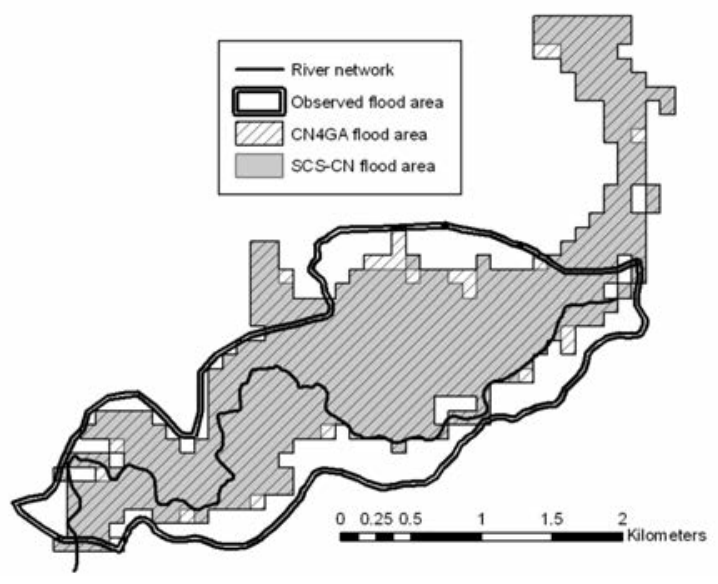

Figure 4. Results of 2D hydraulic modeling. Observed, SCS-CN and CN4GA flooded areas application. However, considering only the area that has been flooded, the CN4GA application provides, with reference to the SCS-CN application, 19 more cells, each one characterized by an area corresponding to 1 hectare, that appears to be inundated as it happened, while this situation does not happen with the SCS-CN application. This is mainly due to the fact that CN4GA rainfall-runoff modeling provides a higher peak discharge, resulting in a greater flooded volume and area. Anyway, differences among the flooded areas are moderate: SCS-CN flooded area is $4.26 \mathrm{~km}^{2}$, and CN4GA flooded area is $4.49 \mathrm{~km}^{2}$, being the differences around 5\%. Regarding total flooded volumes, SCS-CN is $13,170,000 \mathrm{~m}^{3}$, while CN4GA is $14,930,400 \mathrm{~m}^{3}$, with a difference of $13 \%$.

\section{Conclusions}

A recently proposed mixed procedure, named CN4GA, specifically designed to distribute in time - according to the Green-Ampt infiltration equation - the total runoff volume provided by the SCS-CN method, is here applied on a case study in Central Italy in hydrologic-hydraulic event-based approach to derive flood maps. Three flood maps have been compared: one observed and digitized from aerial photos, two simulated with event-based approach adopting CN4GA and SCS-CN methods in the net rainfall step. The results show that the CN4GA modeled flood area is more similar to the observed one, although differences are moderate, being around $5 \%$ for flooded areas and $13 \%$ for flooded volumes among the two modeling approaches.

\section{References}

CORINE (Coordination of Information on Environment) Project, 2000. CORINE Database, a key database for European integrated environmental assessment. Programme of the European Commission, European Environmental Agency (EEA).

Dodov, B., Foufoula-Georgiou, E., 2006. Floodplain morphometry extraction from a high resolution digital elevation model: a simple algorithm for regional analysis studies. IEEE Geosci. Remote Sens. Lett. 3 (3), 410-3.

European Directive 2007/60

FL0-2D. 2012. FLO-2D Reference Manual (https://www.flo-2d.com/)

Green WH, Ampt GA. 1911. Studies on soil physics. J. Agr. Sci. 4(1): 124.

Grimaldi S, Petroselli A, Alonso G., Nardi F. 2010. Flow Time estimation with variable hillslope velocity in ungauged basins. Adv. Water Resour. 33:1216-23,

Grimaldi S, Petroselli A, Nardi F. 2012. A parsimonious geomorphological unit hydrograph for rainfall runoff modeling in small ungauged basins. Hydrolog. Sci. J. 57(1): 73-83.

Grimaldi, S., Petroselli, A., Arcangeletti, E., Nardi, F., 2013a. Flood mapping in ungauged basins using fully continuous hydrologichydraulic modeling. J. Hydrol. 487:39-47.

Grimaldi, S., Petroselli, A., Romano, N. 2013b. Green-Ampt CurveNumber mixed procedure as an empirical tool for rainfall-runoff modelling in small and ungauged basins. Hydrol. Process. 27(8):1253-64

Grimaldi, S., Petroselli, A., Romano, N. 2013c. Curve-Number/GreenAmpt mixed procedure for streamflow predictions in ungauged basins: Parameter sensitivity analysis. Hydrol. Process. 27(8):1265-75

Horritt, M.S., Di Baldassarre, G., Bates, P.D., Brath, A., 2007. Comparing the performance of a 2-D finite element and a 2-D finite volume 
model of floodplain inundation using airborne SAR imagery. Hydrol. Process. 21:2745-59http://dx.doi.org/10.1002/hyp. 6486.

Mein RG, Larson CL. 1973. Modeling infiltration during a steady rain. Water Resour. Res. 9(2): 384-94.

Nardi, F., Vivoni, E.R., Grimaldi, S., 2006. Investigating a floodplain scaling relation using a hydrogeomorphic delineation method. Water Resour. Res. 42, W09409. http://dx.doi.org/10.1029/2005WR004155.

Natural Resources Conservation Service (NRCS). 2008. part 630 Hydrology, National Engineering Handbook. U.S. Department of Agriculture: Washington, DC.

Petroselli, A., 2012. LIDAR Data and Hydrological Applications at the
Basin Scale. GIScience \& 652 Remote Sensing, 49(1): 139-62.

Sampson, C.C., Fewtrell, T.J., Duncan, A., Shaad, K., Horritt, M.S., Bates, P.D., 2012. Use of terrestrial laser scanning data to drive decimetric resolution urban inundation models Adv. Water Resour. 41:1-17,

Soil Conservation Service (SCS). 1972. National Engineering Handbook, Section 4, Hydrology, (NEH-4), U.S. Department of Agriculture, Washington D.C..

USDA-NRCS. 2010. National Engineering Handbook, Part 630 Hydrology. (http://www.info.usda.gov/viewerFS.aspx?hid=21422). 